NASA/TM-2009-215828

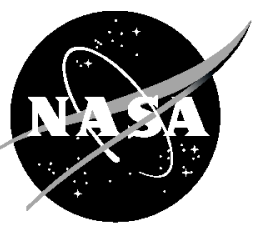

\title{
Progress Towards the Remote Sensing of Aircraft Icing Hazards
}

Andrew Reehorst and David Brinker

Glenn Research Center, Cleveland, Ohio

Marcia Politovich and David Serke

National Center for Atmospheric Research, Boulder, Colorado

Charles Ryerson

U.S. Army Cold Regions Research and Engineering Laboratory, Hanover, New Hampshire

Andrew Pazmany

ProSensing, Inc., Amherst, Massachusetts

Fredrick Solheim

Radiometrics Corporation, Boulder, Colorado 


\section{NASA STI Program . . . in Profile}

Since its founding, NASA has been dedicated to the advancement of aeronautics and space science. The NASA Scientific and Technical Information (STI) program plays a key part in helping NASA maintain this important role.

The NASA STI Program operates under the auspices of the Agency Chief Information Officer. It collects, organizes, provides for archiving, and disseminates NASA's STI. The NASA STI program provides access to the NASA Aeronautics and Space Database and its public interface, the NASA Technical Reports Server, thus providing one of the largest collections of aeronautical and space science STI in the world. Results are published in both non-NASA channels and by NASA in the NASA STI Report Series, which includes the following report types:

- TECHNICAL PUBLICATION. Reports of completed research or a major significant phase of research that present the results of NASA programs and include extensive data or theoretical analysis. Includes compilations of significant scientific and technical data and information deemed to be of continuing reference value. NASA counterpart of peer-reviewed formal professional papers but has less stringent limitations on manuscript length and extent of graphic presentations.

- TECHNICAL MEMORANDUM. Scientific and technical findings that are preliminary or of specialized interest, e.g., quick release reports, working papers, and bibliographies that contain minimal annotation. Does not contain extensive analysis.

- CONTRACTOR REPORT. Scientific and technical findings by NASA-sponsored contractors and grantees.
- CONFERENCE PUBLICATION. Collected papers from scientific and technical conferences, symposia, seminars, or other meetings sponsored or cosponsored by NASA.

- SPECIAL PUBLICATION. Scientific, technical, or historical information from NASA programs, projects, and missions, often concerned with subjects having substantial public interest.

- TECHNICAL TRANSLATION. Englishlanguage translations of foreign scientific and technical material pertinent to NASA's mission.

Specialized services also include creating custom thesauri, building customized databases, organizing and publishing research results.

For more information about the NASA STI program, see the following:

- Access the NASA STI program home page at http://www.sti.nasa.gov

- E-mail your question via the Internet to help@ sti.nasa.gov

- Fax your question to the NASA STI Help Desk at $443-757-5803$

- Telephone the NASA STI Help Desk at 443-757-5802

- Write to: NASA Center for AeroSpace Information (CASI) 7115 Standard Drive Hanover, MD 21076-1320 
NASA/TM-2009-215828

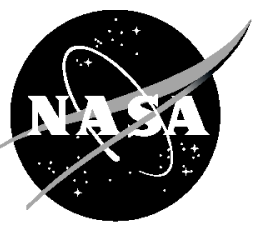

\section{Progress Towards the Remote Sensing of Aircraft Icing Hazards}

Andrew Reehorst and David Brinker

Glenn Research Center, Cleveland, Ohio

Marcia Politovich and David Serke

National Center for Atmospheric Research, Boulder, Colorado

Charles Ryerson

U.S. Army Cold Regions Research and Engineering Laboratory, Hanover, New Hampshire

Andrew Pazmany

ProSensing, Inc., Amherst, Massachusetts

Fredrick Solheim

Radiometrics Corporation, Boulder, Colorado

Prepared for the

Optics and Photonics

sponsored by SPIE

San Diego, California, August 10-14, 2008

National Aeronautics and

Space Administration

Glenn Research Center

Cleveland, Ohio 44135 
Trade names and trademarks are used in this report for identification only. Their usage does not constitute an official endorsement, either expressed or implied, by the National Aeronautics and Space Administration.

Level of Review: This material has been technically reviewed by technical management.

Available from

NASA Center for Aerospace Information

7115 Standard Drive

Hanover, MD 21076-1320
National Technical Information Service 5285 Port Royal Road Springfield, VA 22161

Available electronically at http://gltrs.grc.nasa.gov 


\title{
Progress Towards the Remote Sensing of Aircraft Icing Hazards
}

\author{
Andrew Reehorst and David Brinker \\ National Aeronautics and Space Administration \\ Glenn Research Center \\ Cleveland, Ohio 44135 \\ Marcia Politovich and David Serke \\ National Center for Atmospheric Research \\ Boulder, Colorado 80307 \\ Charles Ryerson \\ U.S. Army Cold Regions Research and Engineering Laboratory \\ Hanover, New Hampshire 03755 \\ Andrew Pazmany \\ ProSensing, Inc. \\ Amherst, Massachusetts 01002 \\ Fredrick Solheim \\ Radiometrics Corporation \\ Boulder, Colorado 80301
}

\begin{abstract}
NASA has teamed with the FAA, DoD, industry, and academia for research into the remote detection and measurement of atmospheric conditions leading to aircraft icing hazards. The ultimate goal of this effort is to provide pilots, controllers, and dispatchers sufficient information to allow aircraft to avoid or minimize their exposure to the hazards of in-flight icing. Since the hazard of in-flight icing is the outcome of aircraft flight through clouds containing supercooled liquid water and strongly influenced by the aircraft's speed and configuration and by the length of exposure, the hazard cannot be directly detected, but must be inferred based upon the measurement of conducive atmospheric conditions. Therefore, icing hazard detection is accomplished through the detection and measurement of liquid water in regions of measured sub-freezing air temperatures. The icing environment is currently remotely measured from the ground with a system fusing radar, lidar, and multifrequency microwave radiometer sensors. Based upon expected ice accretion severity for the measured environment, a resultant aircraft hazard is then calculated. Because of the power, size, weight, and view angle constraints of airborne platforms, the current ground-based solution is not applicable for flight. Two current airborne concepts are based upon the use of either multifrequency radiometers or multifrequency radar. Both ground-based and airborne solutions are required for the future since ground-based systems can provide hazard detection for all aircraft in airport terminal regions while airborne systems will be needed to provide equipped aircraft with flight path coverage between terminal regions.
\end{abstract}

\subsection{Introduction}

Aircraft Icing is a significant flight hazard that continues to be a major concern to the flying community (Ref. 1). A recent search of the Aircraft Owners and Pilots Association (AOPA) Accident Analysis Web site (Ref. 2) produced 62 structural in-flight icing accident reports covering the period from January 1999 to December 2007, where about half of these accidents resulted in fatalities. The severity of icing conditions can vary considerably both spatially and temporally, so that one aircraft may encounter 
no perceptible icing while a trailing aircraft may encounter severe icing (Ref. 3 ). These factors conspire to make the accurate prediction of in-flight icing conditions very important, yet very difficult. While great progress has been achieved recently in the diagnosis and prediction of icing based on meteorological models and station reports (Ref. 4), the demand for the direct detection and measurement of hazardous flight icing conditions continues.

Aircraft ice accretion typically occurs when an aircraft surface impacts supercooled liquid water. Depending on the amount of liquid water present, the size of the cloud droplets, the air temperature, the aircraft surface geometry, and the aircraft speed, the water will freeze immediately (typically lower water contents, smaller droplet sizes, and colder temperatures) which results in a generally conformal rime ice, or will flow on the surface before freezing (typically higher water contents, larger droplets, and warmer freezing temperatures) which results in the more hazardous, nonconformal glaze ice. Since aircraft icing is a process that requires the presence of an aircraft to occur, it cannot be directly measured remotely. Instead, it is the detection and measurement of the conditions that lead to aircraft icing in which we are interested. So, when we speak of the remote detection of aircraft icing, we are really speaking of the detection and measurement of supercooled liquid water. The current techniques for the remote detection and measurement of icing conditions rely on the identification and measurement of liquid water and then the inference or measurement of the surrounding air's temperature.

To provide coverage for the maximum number of aircraft over the maximum extent of their flight path, both ground-based and airborne icing remote sensing solutions are desired. While ideally all aircraft would be equipped with icing remote detection equipment to provide information coverage over their entire flight paths, this will practically never happen. So providing a ground-based capability that can provide information to all aircraft entering and departing a terminal area (where the greatest icing threat exists due to altitude and aircraft configuration constraints) and equipping some aircraft with an airborne capability to cover regions between terminal areas is seen as the best possible solution. Conceptual drawings of the ground-based and airborne capabilities are shown in Figures 1 and 2.

The work described in this paper is being pursued under the NASA Aviation Safety Program's Integrated Intelligent Flight Deck (IIFD) Project. Specifically, the research and development of remote detection and measurement of aircraft icing hazards is a part of the IIFD External Hazards Detection (EHD) element. While we are showing conceptual user interfaces here, the scope of the work being reported is focused on the sensing and characterizing of the external icing environment. EHD and IIFD have defined tasks to take the output of such sensing systems and determine expected flight path hazards, provide guidance to flight crews, and share the information to the airspace system. Since these sensor systems should provide extensive real-time environment assessment data, further linkage to FAA and NWS forecasting and nowcasting systems is also anticipated.

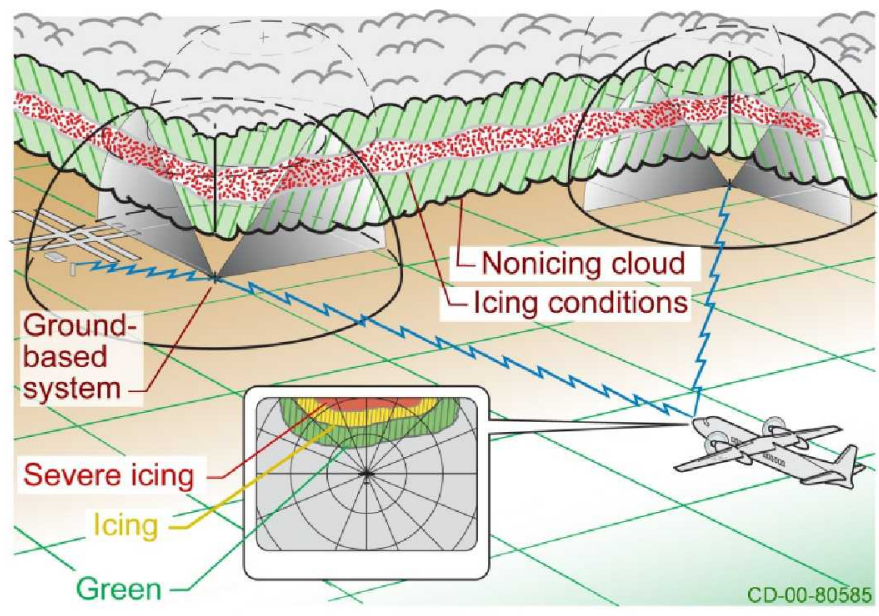

Figure 1.-Ground-based remote sensing concept. 


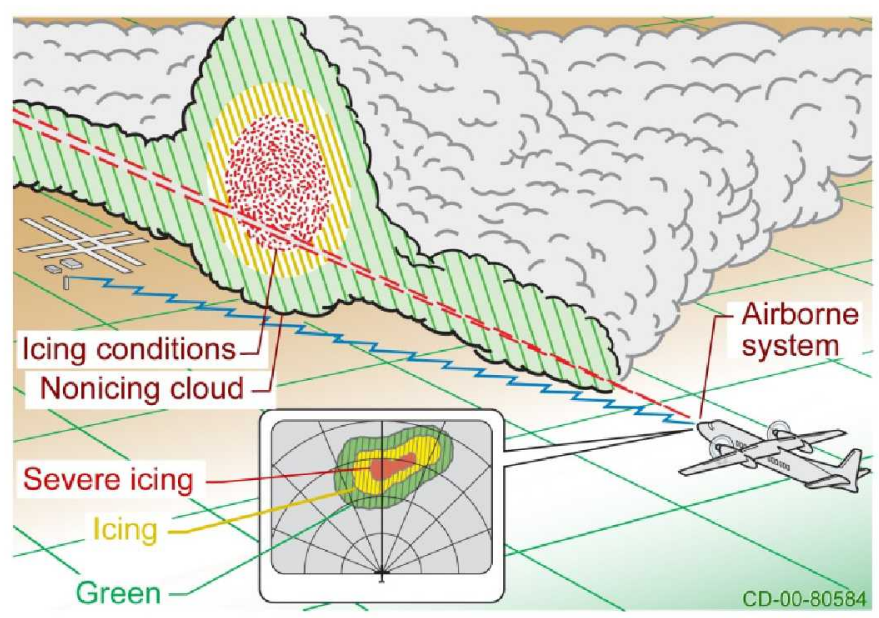

Figure 2.-Airborne remote sensing concept.

\subsection{Ground-Based Remote Sensing Development}

\subsection{Background}

The development of a ground-based hazard detection algorithm testbed, the NASA Icing Remote Sensing System (NIRSS), was begun in 1997 (Ref. 5). Ground-based detection was the first area of interest because it is not constrained by the space/power/weight limitations of flight systems. It was decided that initial efforts would be made with ground systems to prove basic icing remote sensing feasibility and then move to flight systems as technical maturity and programmatic constraints allowed. The objective of the ground-based system development is to provide accurate detection and warning of in-flight icing conditions in the near-airport environment with proven, cost effective, off-the-shelf meteorological sensing hardware.

\subsection{Instrumentation}

NIRSS utilizes a 3000 series multichannel radiometer (Ref. 6) built by Radiometrics Corporation. Ground-based passive microwave radiometers have the ability to profile temperature and water vapor in the atmosphere. They can also directly quantify total integrated liquid water between the antenna and the top of the atmosphere, and obtain low resolution profiles of liquid water; however this resolution is generally inadequate for our application. Weather radars have good range resolution of reflectivity to determine where clouds are and give some information on their composition, but do not measure water vapor, temperature or liquid water content. There is therefore synergism between these two sensing platforms, provided that they can simultaneously sample the same volume. Microwave radiometer beamwidths are typically several times wider than those of weather radars, but are sufficient for most meteorological applications, allowing the use of more compact and economical antennas. However, to match the sample volume of weather radars, much larger apertures and accurate pointing are required.

Radiometric temperature profiling can be accomplished by profiling the downwelling spectrum on either side of the broad assemblage of oxygen transitions centered on $60 \mathrm{GHz}$ and spanning from approximately 50 to $70 \mathrm{GHz}$. Oxygen emits proportional to its physical temperature, and the varying attenuation from the center of this feature out onto the wings yields range (altitude) information. Water vapor profiling can be accomplished by measuring the pressure broadening of the water vapor emission line at 22 or $183 \mathrm{GHz}$. Because the shape of these lines is dependent upon local pressure, information on the pressure altitude is contained in the emission profile, and density upon the intensity of the line. Cloud liquid water has no emission lines, but emits over a broad range of frequencies roughly as the square of the frequency. By observing widely disparate frequencies across the microwave spectrum, integrated 


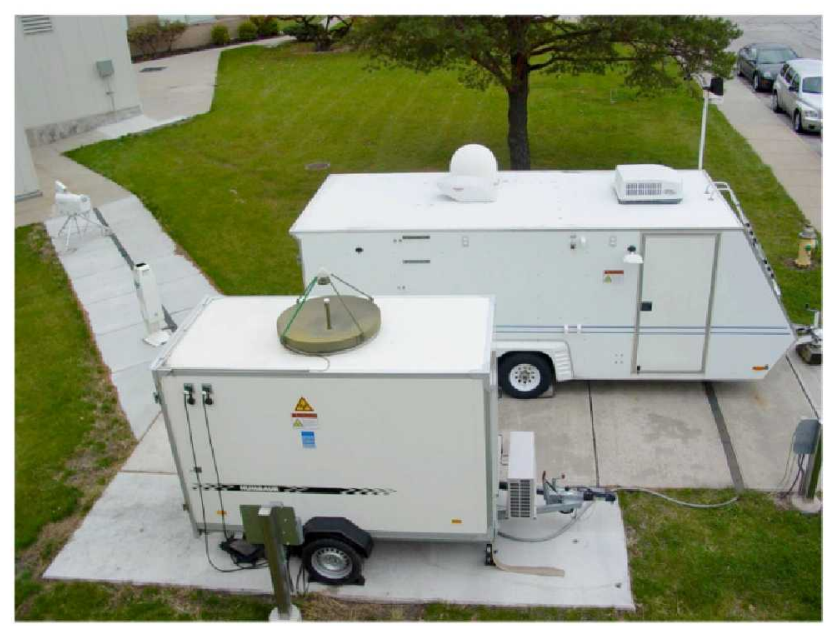

Figure 3.-NASA's icing remote sensing site. Includes the larger trailer which houses the X-band radar (under the radome) and the instrument computers, the Radiometrics 3000 series radiometer at the top left, the Vaisala ceilometer to the left, and the Metek Ka-band radar housed in the smaller trailer at the bottom of the photo.

liquid water (ILW) measurements can be obtained. Including climatology as a priori information increases the skill of obtaining these measurements. The radiometer also has a vertically-pointing sensor which measures the infrared temperature (IRT) of the cloud base.

A modified Honeywell WU-870 airborne X-band radar in a vertically-staring configuration is mounted atop the trailer which houses the system's data fusion hardware (Fig. 3). X-band radar was chosen over longer wavelengths because the systems are generally cheaper and antennas are smaller. $\mathrm{X}$-band also allows some sensitivity to cloud-sized water drops or ice crystals while not becoming significantly attenuated as are shorter wavelengths. A Vaisala laser ceilometer completes the current system configuration.

\subsection{Software Logic}

The instrument data are ingested into three separate computers within the NIRSS trailer for display and storage. The three raw data streams are pushed to a Linux machine where the fusion processing and hazard detection software reside. The processing begins by combining the radar and ceilometer data to determine where cloud layers exist. Ceilometer data are relied upon to determine cloud base heights in cases of light precipitation. If the radar reflectivity (REFL) is greater than $1 \mathrm{dBZ}$ above the minimum detectable threshold for at least $\mathbf{2 0 0} \mathrm{m}$ depth, a cloud layer is detected. Shallower clouds are ignored. The radar and ceilometer agree reasonably well during most of the examined case studies. Cloud boundaries are often quite noisy so a 5 min smoothing function is applied at no expense to accuracy or safety.

Through years of in situ analysis, it has been found that the vertical distribution of liquid water in cloud layers cannot be determined accurately and reliably, even with the aid of external clues such as temperature range or cloud depth. Unless a full-blown cloud microphysics model is run with good initialization data including appropriate cloud active nuclei concentrations, one would still need to make assumptions about the liquid water profile given previous measurements of liquid water and ice versus water composition. NIRSS employs a simple fuzzy logic approach to estimate the liquid water profile, which can easily be modified in future upgrades as more case studies are collected and analyzed. For each cloud layer we have cloud top, base and depth. For the whole vertical column we have ILW, as well as temperature and REFL distributions with height. ILW for each cloud layer is assigned based on cloud depth and the coldest temperature in the layer. 
The algorithm assumes four possible distributions of liquid within the cloud: uniform (same LWC for every level); wedge (from zero at the base to a maximum at the top); weighted by temperature (assume colder clouds with mixed-phase conditions have less water and more ice as the temperature is lower); and weighted by REFL ${ }^{1 / 2}$ (an approximation (Ref. 7) for nonprecipitating clouds). The final calculated profile will be a combination of these four distributions scaled by weighting factors $\left(a_{\text {Uniform }}, a_{W e d g e}, a_{T e m p}\right.$, and $a_{\text {REFL }}$ ) for each, which are characteristics of the cloud that are derived from the data. These characteristics and weighting functions can differ for each cloud layer. Many combinations of weights are possible and they will depend on what we can learn about the cloud structure with the NIRSS measurements. Next, a determination about the cloud layer's phase is made. If a cloud layer's base temperature is greater than $260 \mathrm{~K}$ and its REFL is less than $10 \mathrm{dBZ}$ above the minimum detectable, the layer is deemed to be liquid phase. Otherwise, the layer is categorized as mixed phase. The layer's LWC profile is then calculated with the weighting functions shown in Table 1, which have been derived from ongoing analysis of icing research aircraft flights. Having determined the heights of clouds and having the LWC and temperature profiles within them, a qualitative in-flight icing scheme (Ref. 8) is employed assuming a 15- $\mu \mathrm{m}$ drop size. The NIRSS display shows severity categories as designated in Table 2.

TABLE 1.-WEIGHTING FUNCTIONS FOR FOUR METHODS OF DISTRIBUTING LIQUID WATER IN CLOUD LAYERS FOR LIQUID AND MIXED PHASE CLOUDS

\begin{tabular}{|c|c|c|}
\hline Weighting function & Liquid cloud & Mixed cloud \\
\hline $\mathrm{a}_{\text {Uniform }}$ & 0.1 & 0.15 \\
\hline $\mathrm{a}_{\text {Wedqe }}$ & 0.3 & 0.25 \\
\hline $\mathrm{a}_{\text {Temp }}$ & 0.1 & 0.5 \\
\hline $\mathrm{a}_{\text {REFL }}$ & 0.5 & 0.1 \\
\hline
\end{tabular}

TABLE 2.-ICING SEVERITY CATEGORIES AND CORRESPONDING LWC VALUES SHOWN ON THE NIRSS ICING HAZARD DISPLAY

\begin{tabular}{|c|c|}
\hline LWC $\left(\mathrm{gm}^{-3}\right)$ & Icing severity \\
\hline$<0.01$ & No icing \\
\hline 0.01 to 0.017 & Trace \\
\hline 0.017 to 0.03 & Trace-light \\
\hline 0.031 to 0.066 & Light \\
\hline 0.067 to 0.012 & Light-moderate \\
\hline 0.02 to 0.2 & Moderate \\
\hline 0.20 to 0.37 & Moderate-heavy \\
\hline$>0.37$ & Heavy \\
\hline
\end{tabular}

\subsection{Recent Progress}

Many important improvements have been implemented within NIRSS in the last several years. The fusion software has been recoded from LabVIEW to $\mathrm{C}++$ language, and the display software has been recoded in the Java language. Realtime processing and analysis of data are now possible within the system trailer, and processed data and imagery are now automatically pushed to the web (http://iceboxesn.grc.nasa.gov/RSData/index.html).

One recent enhancement to the NIRSS logic software is an algorithm which adjusts the radiometer's temperature profile in cases of significant temperature inversions. Previous research has shown that radiometers often do poorly in detecting inversions (Ref. 9) due to their low vertical resolution, and also that inversions often are associated with the upper extent of significant super-cooled liquid water (SLW) (Ref. 10). If inversions are not accurately detected, ILW might be spread over a larger vertical range, thus 
decreasing the detected severity. The new algorithm tests if the IRT is greater than $3^{\circ}$ less than the radiometer derived temperature at cloud base. If so, the profile is rebuilt at the moist adiabatic lapse rate from the IRT through the cloud depth. An inversion with a fixed lapse rate is created starting at cloud top and then the rebuilt profile is gradually merged back to the radiometer's profile by $2 \mathrm{~km}$ above the rebuilt inversion. Another enhancement is the quantitative use of the REFL field to warn on small-drop icing situations (Ref. 11).

Work is ongoing to compare the icing severity output fields from NIRSS to NCAR's Current Icing Product (CIP) and pilot reports (PIREPs). It is important to note that PIREPs are not considered highly accurate indicators of icing severity as they are prone to recording displacements in time and space and are also subjective measurements by an otherwise busy pilot. They are, however, the best measure of in situ icing hazard available short of research aircraft data. PIREP icing severities are scaled as $\mathbf{0}$ for null, 1 to 8 for trace to heavy.

An icing case where NIRSS was deployed at Cleveland's Hopkins International Airport (KCLE) from 0000 UTC on 26 February through 1600 UTC on 27 February, 2008 is shown in Figure 4. Starting just before $0000 \mathrm{UTC}$ on the $26 \mathrm{th}$, CIP detected light icing up to $18 \mathrm{Kft}^{1}$ which builds gradually down toward the surface by 0700 UTC on the 26th. A moderate PIREP, shown as a vertical stack of 5 's on the upper CIP severity plot, was reported around 0300 UTC from 10 to $14 \mathrm{Kft}$. NIRSS diagnosed trace to light icing in the same altitude ranges as CIP from before 0000 to 0500 UTC, with light icing shown at the time and altitude of the moderate icing PIREP. At 0500 UTC, it began snowing at KCLE and continued through 1200 UTC on the 26th. The snow production and precipitation processes in clouds are well known to scour most available liquid water through accretion of liquid to ice particles. NIRSS had an obvious gap in icing hazard profile from 0500 to 1300 UTC during the times of significant precipitation rate at KCLE, but CIP icing severity actually increased to moderate, with some altitudes showing heavy severities. This is due to a known problem with CIP at night (through 1300 UTC for KCLE) where the algorithm loses its visible GOES input and relies too heavily on GOES IR channels. From 1300 to 2400 UTC, precipitation rates decreased to intermittent trace amounts. CIP detects moderate severities generally from 4 to $18 \mathrm{Kft}$ during the period. NIRSS showed periodic trace severities from 1 to $14 \mathrm{Kft}$ during the period.

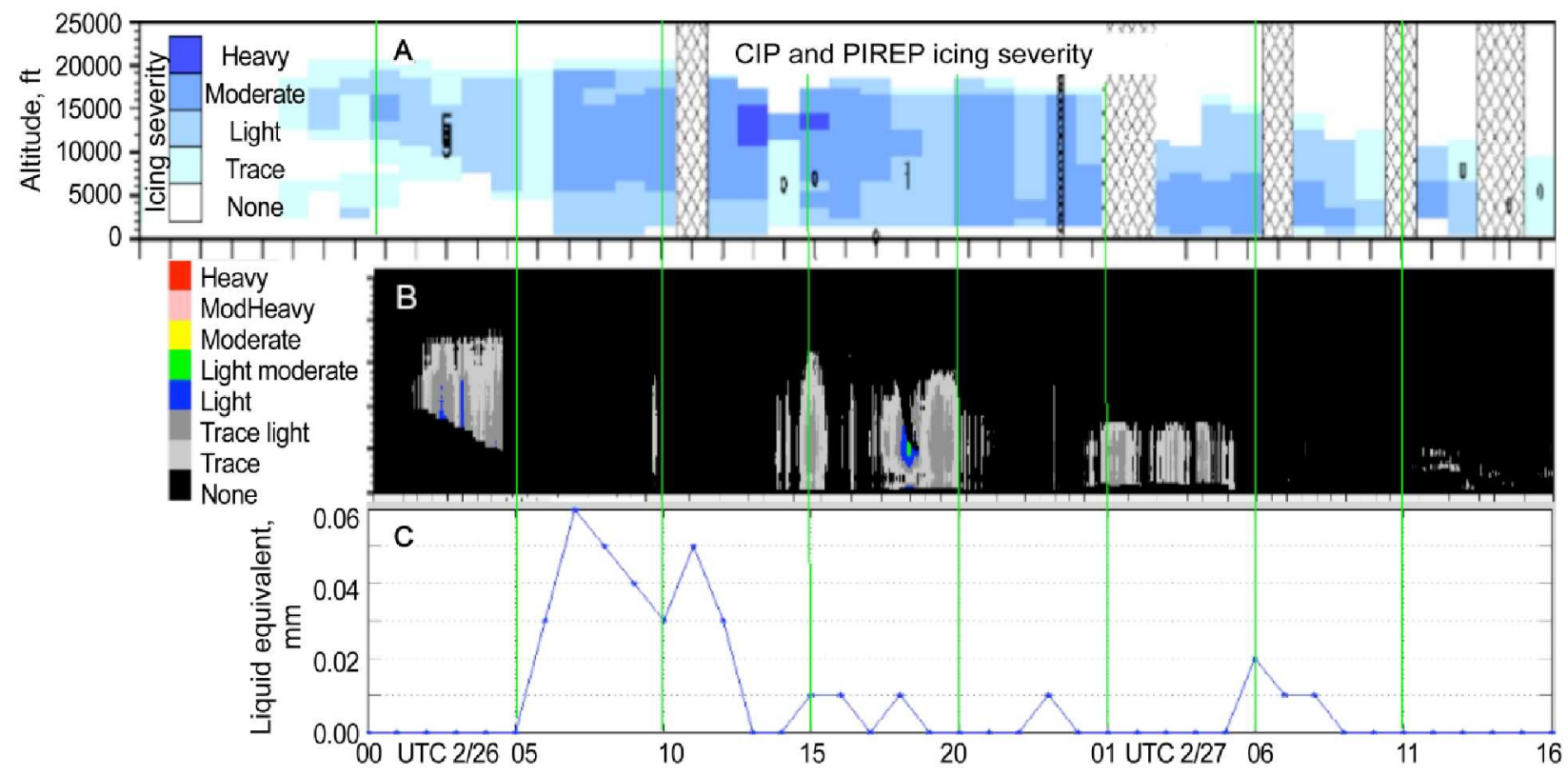

Figure 4.-CIP (A) and NIRSS (B) derived in-flight icing severity over KCLE from 0000 UTC on February 26, 2008 to 1600 UTC on February 27, 2008. Precipitation rates recorded at KCLE are shown in part C.

\footnotetext{
${ }^{1}$ Note that feet, rather than meters, are used in NIRSS since this is the unit convention used in aviation.
} 
Two null PIREPs occurred just after 1400 and $1500 \mathrm{UTC}$ at 7 to $8 \mathrm{Kft}$, respectively. A trace PIREP occurred over KCLE between 8 and $9 \mathrm{Kft}$ just after $1800 \mathrm{UTC}$, which was coincident with light severities by both CIP and NIRSS.NIRSS later missed a light to moderate PIREP recorded somewhere between 1 and $20 \mathrm{Kft}$ just after $23 \mathrm{UTC}$ on the 26th. From 0000 to 1600 UTC on the 27th, both CIP and NIRSS indicated a gradual lowering in heights of the icing layer and diminishing severity through the profile. Several null PIREPs were recorded between 14 and 16 UTC between 4 and $8 \mathrm{Kft}$ that corresponded to no icing in NIRSS and trace in CIP.

Overall, NIRSS and CIP did well in diagnosing similar severities to PIREPs for the case. Both products saw the case evolve similarly in time and altitude ranges. NIRSS seemed to under predict the real extent of hazard in time, but did well with the hazard altitude ranges. NIRSS also seemed to somewhat under predict the severity value when $\Pi \mathrm{LW}$ was detected. Both of these deficiencies could be easily scaled if further case studies confirm the biases. CIP seemed to exhibit an over prediction in severity value at any given time, especially at night when the most significant snow scavenging was known to be occurring. Both the NIRSS and CIP products should be able to be improved upon by case study inter-comparisons such as the one in this work.

\section{$2.5 \quad$ Future Work}

\subsubsection{Software Upgrades}

Several possible upgrades to the existing NIRSS logic will be explored in the future. Examining the three (radar, ceilometer, radiometer) cloud base estimates under different weather conditions may yield additional information on precipitation intensity or type that we can use further within the system. Additional analyses of aircraft research flight data along with NIRSS input data should lead to improvements on the existing simple algorithm for ILW distribution. Another improvement that is needed is refactoring of the $\mathrm{C}++$ codebase to allow for the parameterization of keyword inputs and allow future system hardware generalization. The NIRSS logic code is a body of work in progress, and many improvements have been implemented in the recent past. A software redesign would make the package more flexible for recent and future enhancements.

NIRSS's severity definition is based on the amount of time it takes an aircraft to accrete $1 / 4 \mathrm{in}$. of ice on the leading edge from less than $5 \mathrm{~min}$ which is classified as "severe", to greater than $15 \mathrm{~min}$, which is classified as "light". Work needs to be done to see if adjustments are needed to bring aircraft icing time scales into accord with the severity scales that are being measured with NIRSS. More information could be extracted from the system to make a better estimate of drop size, or at least flag when SLD conditions are expected. This could be accomplished by using vertical profiles of radar REFL along with the rain flag from the radiometer to detect bright bands.

Another important software upgrade would be the inclusion of a module that ingests the closest CIP gridpoint data and NWS balloon sounding data. The possible synergies between the ground-based NIRSS and the model/satellite based CIP icing hazard products should be fully utilized by NIRSS.

\subsubsection{Instrumentation Upgrades}

One area where significant improvement is possible is in determining cloud phase. The Radiometrics $89 / 150 \mathrm{GHz}$ radiometer could help determine when a cloud is mixed phase by examining the ratio of reflected brightness temperatures at the two frequencies. Previous research (Ref. 12) with this channel combination has shown that ice water path and effective particle diameter can be calculated at any viewing angle. Radiometrics Corporation is currently building a scanning "pencil-beam" radiometer for NASA Glenn with channels from 22 to $30 \mathrm{GHz}$ and at $89 \mathrm{GHz}$. The inclusion of vertical and horizontal polarizations at $89 \mathrm{GHz}$ allows for particle phase discrimination as SLW droplets are axial-symmetric and therefore have no preferential scattering polarization. Glaciated particles tend to grow and fall preferentially in one axial dimension, thus creating a larger difference in the polarization channels. 
Upgrading the radar to a Doppler X-band would provide information on mixed phase conditions by being able to classify fall velocities spectra as rimed ice particles, unrimed ice particles or small suspended particle populations (Ref. 13). Rimed particles unequivocally indicate the presence of supercooled liquid.

\subsubsection{Research Flights}

There are good data sets from the NASA Twin Otter, the MSC Convair and the UND Citation from the Second Alliance Icing Research Study (AIRS-II) field project in 2003 and Cleveland-area flights during 2005. Additional research flights with the new NASA S-3 would be extremely valuable to facilitate future NIRSS improvements. Now that the system has been proven to accurately detect icing hazard in its vertically staring configuration, trials should begin to compare the scanning pencil-beam radiometer and the 3000 series multichannel radiometer to the nearby KCLE NEXRAD output and any future icing research aircraft flights. The power of NIRSS to warn of icing hazard in the near airport environment will be greatly enhanced when elevation and azimuth scanning capabilities are implemented and tested.

\subsection{Airborne Remote Sensing Development}

\subsection{Airborne Radar Development}

\subsubsection{Background}

Recent studies (Refs. 14 to 16) concluded that colocated microwave and millimeter wavelength radars can estimate liquid water content and a characteristic drop size of liquid precipitation, suggesting the application of the technology for in-flight sensing of icing potential ahead of aircraft. Although there are some differences between the various retrieval techniques, all the algorithms estimate moments of the drop size distribution from profiles of reflectivity at a weakly attenuating microwave frequency, typically $\mathrm{X}$-band, and a more attenuating microwave frequency, 35 and/or $95 \mathrm{GHz}$. The microwave channel is highly sensitive to drop size, as the reflected power is proportional to the sixth moment of the drop size distribution $\left(\mathrm{p}_{\mathrm{r}}=\mathrm{f}\left(\Sigma \mathrm{D}_{\mathrm{i}}^{6}\right)\right)$ (for Rayleigh scatterers), while the differential attenuation, between the microwave and millimeter wave channels, can be related to liquid water content. After successful groundbased tests, the Icing Branch of the NASA Glenn Research Center began collaborating with ProSensing Inc. to develop an airborne, multifrequency radar to test the technique in realistic in-flight icing conditions.

\subsubsection{Instrumentation}

The NASA Multifrequency radar (MFR) system was designed with $2 \mathrm{~mm}$ wavelength channels (35 and $95 \mathrm{GHz}$ ) to extend the liquid water range of the sensor and to maintain accuracy in nonRayleigh precipitation. The radar consists of pulsed X $(3 \mathrm{~cm})$ and Ka-band $(1 \mathrm{~cm})$ radars, both employing $25 \mathrm{~kW}$ magnetron transmitters, and a two-antenna Frequency Modulated Continuous-wave (FMCW) W-band ( $3 \mathrm{~mm}$ ) radar. With the RF sections housed in a single forward looking pod, the three radars will sample similar sample volumes with $12,5.5$, and $3 \mathrm{in}$. diameter antennas at 10,35 , and $95 \mathrm{GHz}$, respectively. The $95 \mathrm{GHz}$ antennas are Gaussian optics lenses, while the $\mathrm{Ka}$ and X-band antennas are flat-plate slotted waveguide arrays (left side of Figure 5). When installed on the NASA S-3 aircraft, all three forwardlooking radars will transmit and receive horizontally polarized signals. The front section of the pod, shown on the right of Figure 5, contains the antennas and a hemispherical $\mathrm{X}$-band radome and the $\mathrm{Ka}$ and W-band Rexolite radome windows tilted at the Brewster angle for maximum signal transmission. 


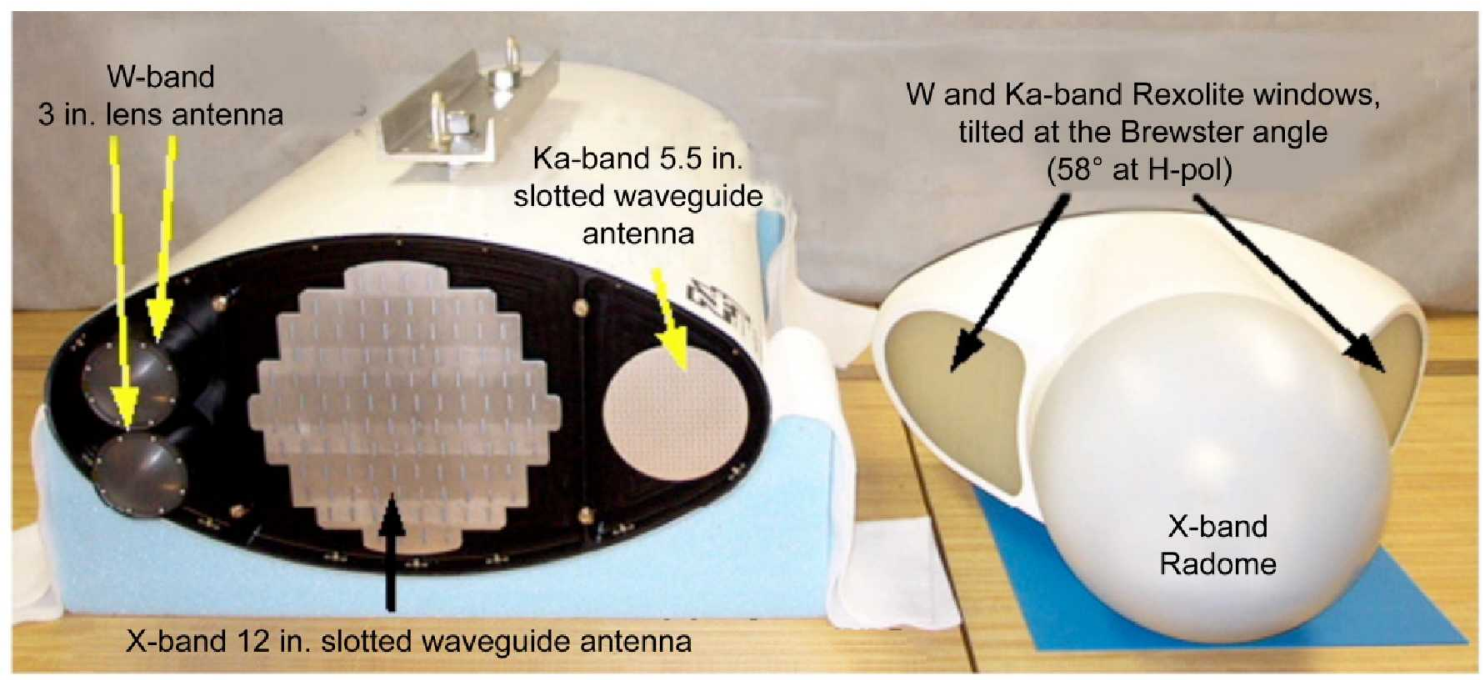

Figure 5.-The NASA Multifrequency Radar (MFR) system pod section, containing an $X(9.4 \mathrm{GHz})$ and Ka-band $(35 \mathrm{GHz})$ pulsed radars and a W-band $(95 \mathrm{GHz})$ FMCW radar system.

\subsubsection{Data Analysis}

In a 1998 study (Ref. 17), a working hypothesis that cloud parameters could be extracted by measuring backscatter at a combination of attenuating and nonattenuating frequencies was developed. Since scattering is a complex nonlinear function of particle size and frequency, it is impractical to consider an analytical solution to the inverse problem of computing particle size and liquid water content based on measured backscattered power at multiple frequencies. The analysis effort for the MFR is therefore focused on an approximate numerical solution to the inversion, specifically, a neural network. Neural nets are ideal for solving problems where the forward problem is well characterized but the inverse is nonlinear and complicated. The neural net programming process starts with the generation of a training set of statistically significant atmospheric conditions. This took the form of profiles of drop size distributions. From these drop distributions, a computer algorithm calculated the corresponding radar observed reflectivity profiles at each operating frequency as well as resultant LWC and drop size in each volume cell. Gaussian distributed random variables were added to the reflectivity profiles to simulate the effect of noise in the data. This set of multifrequency reflectivity profiles (inputs) and cloud and precipitation parameter profiles (outputs) were then used to train the neural network (Ref. 15). The network was trained by simulating thousands of test cases of radar scattering from assumed particle size distributions.

\subsubsection{Progress}

$\mathrm{X}, \mathrm{Ka}$, and W-band data from the Mt. Washington Icing Sensors Project (MWISP) (Ref. 18) were analyzed with the neural net. Figure 6 shows the comparison of the neural net retrieval's LWC profile to that measured with the ATEK LWC profiling radiosonde. The astericks show the average LWC as derived by the neural network. These points were computed by taking 12-min averages of the neural network derived LWC at each altitude. Figure 6 shows good agreement between the in-situ radiosonde derived LWC and the neural networks output. The measurements show agreement both in the altitude distribution (within the resolution of the measurement) and peak value (within 20 percent). Further time history plots and the corresponding weather observations are included in Pazmany's 2001 report (Ref. 15). 


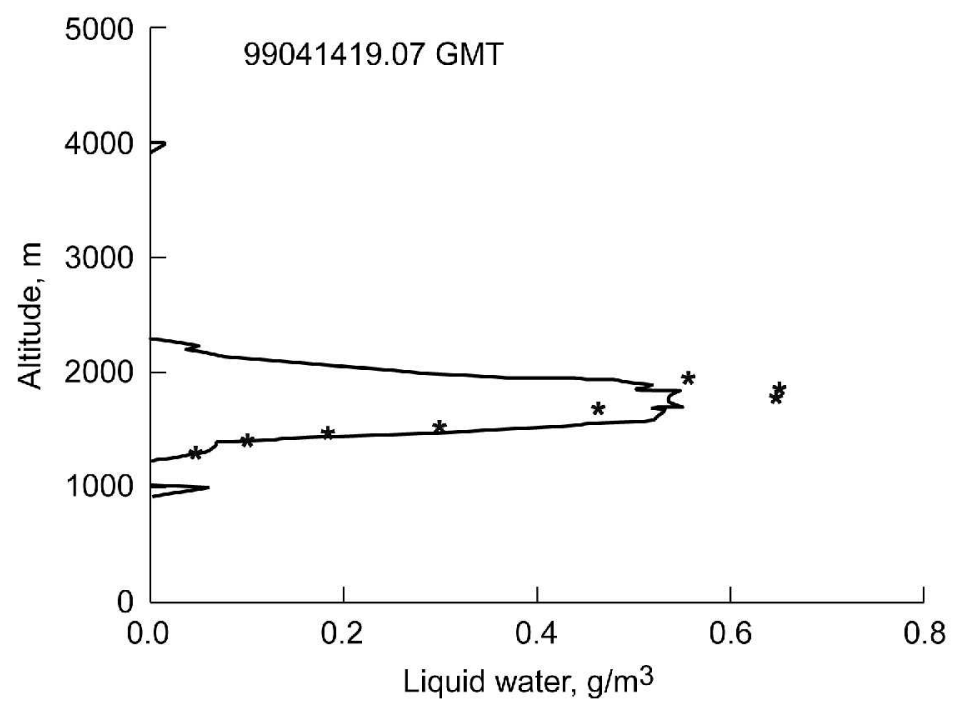

Figure 6.-Coincident 10, 35, and $95 \mathrm{GHz}$ Radar derived liquid water profile from MWISP field project marked with *. Comparison to ATEK radiosonde in-situ LWC measurements marked with line.

\subsubsection{Future Work}

The MFR system is expected to be delivered to NASA following modification in the latter part of 2008. Following delivery to NASA, testing is planned in the NASA Icing Research Tunnel (IRT) to assess the ice accretion patterns on the $\mathrm{X}$-band radome and the $\mathrm{Ka}$ and $\mathrm{W}$-band windows and to assess its general airworthiness. Following this IRT testing and vertical staring ground-based evaluation of the radar system, the MFR will be installed and tested on the NASA S-3 aircraft.

\subsection{Microwave Radiometry}

\subsubsection{Concepts}

A passive airborne approach has been developed by the Army Corps of Engineers Cold Regions Research and Engineering Laboratory (CRREL) using microwave radiometers to detect icing conditions ahead of aircraft. Millimeter wave (MMW) radiometry offers the potential of smaller size, less weight, lower power consumption and lower cost than active systems. CRREL is working with systems operating near 35 and $94 \mathrm{GHz}$.

Microwave radiometers operate by receiving thermal energy from atmospheric constituents at specific wavelengths in the electromagnetic spectrum. Passive microwave radiometers traditionally measure atmospheric and terrestrial characteristics from ground-based, such as NIRSS, and satellite-borne systems. However, their ability to measure atmospheric temperature, cloud liquid water content, and attributes of cloud and precipitation constituents, especially viewing along a near-horizontal flight path, is less well developed. The radiation intensity observed by a radiometer is a function of the temperature, reflectivity, transmissivity, and emissivity of the emitter and attenuation by constituents between the emitter and the radiometer at the wavelength of interest.

Gas, liquid, and solid atmospheric constituents each have unique absorption and emission spectra due to their dielectric properties. As a result, the atmosphere absorbs in several narrow wavelength bands and allows radiation to be transmitted through several broad windows. The primary absorbers are oxygen and water vapor. Oxygen absorbs and reemits in the 50 to $60-\mathrm{GHz}$ region and at $118 \mathrm{GHz}$ and is used for temperature profiling. Water vapor has peak absorption and reemission at 22,37 , and $183 \mathrm{GHz}(\mathrm{Ref} .19)$. Peak absorption and emission of liquid water occurs near 37 and $89 \mathrm{GHz}$. Though the dielectric strength of water is sufficiently high that is absorbs and emits strongly, the frequency-dependent dielectric strength 
of ice is approximately 10 percent of that of water in the millimeter wave spectrum. Therefore, to a MMW radiometer the brightness temperature of water clouds of a given water content tend to be greater than the brightness temperature of ice clouds of a similar amount of frozen water. Therefore, supercooled water clouds are generally more easily detected by microwave radiometers, an advantage because they present the greatest hazard. Ice crystals typically do not adhere to aircraft wings and therefore do not contribute to the icing hazard. However, because water vapor absorbs and emits near $37 \mathrm{GHz}$ and is potentially distributed nonuniformly in the clear atmosphere outside the cloud, the behavior of sensors will also vary within and between flight levels (Ref. 20).

In addition to the absorption, emission, and scattering of atmospheric constituents, the Earth's surface and space both have different signatures in the MMW spectrum. Depending upon materials at the Earth's surface, such as land or water, the Earth's surface will typically provide a large brightness temperature at 35 and $94 \mathrm{GHz}$ because the surface is warm. Conversely, the cold of space provides a small brightness temperature at 35 and $94 \mathrm{GHz}$. These characteristics may be used to advantage to detect conditions ahead of an aircraft through contrast that they provide with the brightness temperature of clouds.

Savage (Ref. 20) and CRREL developed a concept that will allow cloud liquid water content to be derived for clouds, and may provide an estimate of cloud temperature from brightness temperatures. Radiometers placed on the nose of an aircraft could scan ahead of the aircraft horizontally, and $2^{\circ}$ above and below horizontal. In a clear-sky condition, the $2^{\circ}$ beam detects colder temperatures by viewing cold space than does the $-2^{\circ}$ beam looking toward the warmer surface of the Earth. Since the atmosphere is more transmissive at $35 \mathrm{GHz}$, the brightness temperature of the $2^{\circ}$ beam will be less than (colder) than the $2^{\circ} 94 \mathrm{GHz}$ beam. For the downward looking geometry, the brightness temperature difference between 35 and $94 \mathrm{GHz}$ depends on the surface and the atmospheric conditions and is less easily interpreted. The horizontal beam may provide an indication of cloud sensible temperature.

In operation, as the aircraft approaches a cloud, the $2^{\circ}$ beam and the $-2^{\circ}$ beam converge in brightness temperature toward that of the horizontal beam. The rate of convergence to the temperature of the horizontal viewing beam depends on the distance from the cloud, the cloud height above and below the flight altitude, the decrease of air temperature with altitude, and the cloud liquid water content. An estimate of liquid-water content magnitude is obtained by comparing the brightness temperatures of the 35- and 94-GHz beams in the $2^{\circ}$ orientation. Savage et al. (1999) also speculated that the presence of drizzle-size drops can be detected by sensing polarized radiation resulting from drizzle drop scattering of polarized radiation from Earth surfaces, and shape distortion of the largest drops. The $2^{\circ}$ upward-looking and horizontal-looking radiometer concepts may provide the most useful information with regard to locating supercooled water because it does not involve the complexity of changing brightness temperatures emitted or scattered from the Earth's surface.

\subsubsection{Simulation}

We modified the RADTRAN model, developed by the former Air Force Geophysics Laboratory, to model attenuation, scattering and brightness temperatures for 1 to $1000 \mathrm{GHz}$ (Ref. 21). Originally developed to predict brightness temperature and attenuation for ground based and space-based microwave radiometers looking zenith, nadir, or at an angle, RADTRAN calculates the attenuation, transmittance, and brightness temperatures for thermal emission at microwave frequencies using six predefined atmospheric profiles. A capability to model partial or fully glaciated clouds is not available in RADTRAN, though precipitation can be either in a liquid or solid state.

A virtual fly-through capability was created in RADTRAN for simulating in-flight icing. The user specifies the cloud and atmospheric conditions, the frequencies and view directions, the start and end point of the flight path, the number of points along the flight, and the altitude of the flight path. At designated points along the flight path the cloud atmospheric conditions along the view direction are specified. RADTRAN then computes the brightness temperatures, attenuation, and transmission for each frequency and view direction along the flight path location. Figure 7 presents an example of a $37 \mathrm{GHz}$ radiometer with $90^{\circ}$ and $92^{\circ}$ viewing angles used to compute both the distance to a cloud ahead of the 


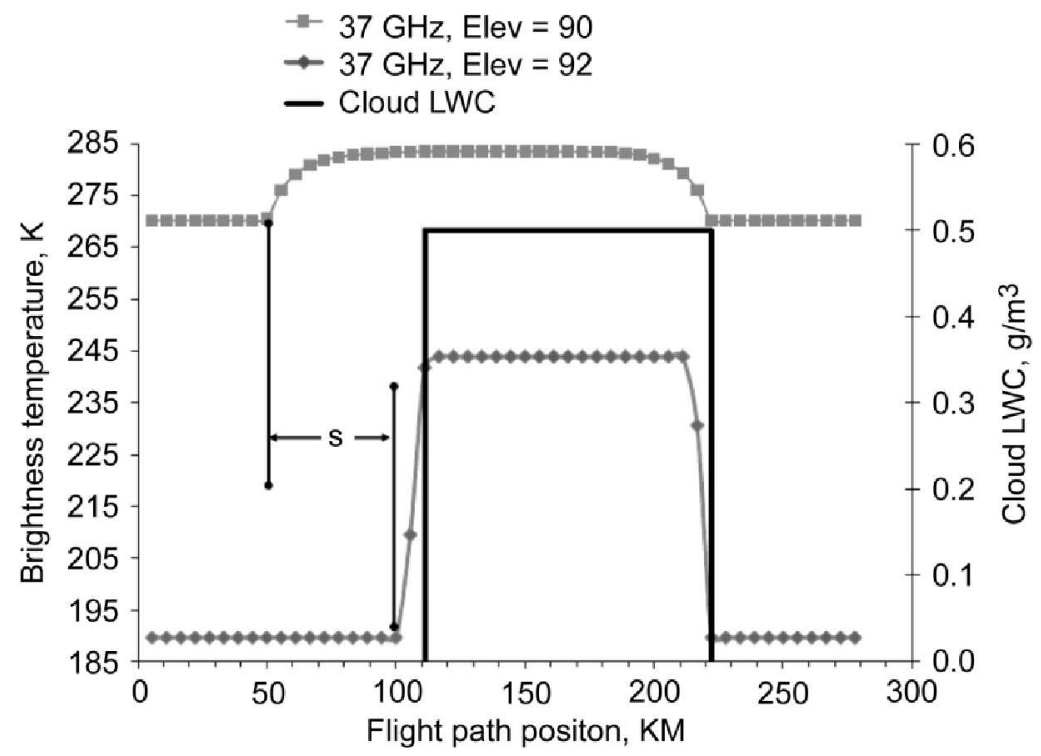

Figure 7.-Brightness temperatures associated with $90^{\circ}$ and $92^{\circ}$ view elevations for radiometers on an aircraft approaching a single cloud.

aircraft and the cloud top altitude for a single cloud with a uniform cloud liquid water content. From the changes in brightness temperature for the two viewing angles, aircraft altitude and the arc distance $S$ between when the $90^{\circ}$ viewing sensor first detects the cloud and the $92^{\circ}$ viewing sensor detects the cloud, it is possible to compute the cloud top altitude and the distance to the cloud from the position when the $92^{\circ}$ viewing sensor first detects the cloud. The calculated cloud top is $0.96 \mathrm{~km}$ and the distance to the cloud is $9.2 \mathrm{~km}$, while the actual values are 1.0 and $10 \mathrm{~km}$, respectively.

Massie et al. (Ref. 22) have developed a neural network model to predict liquid water content for the CRREL system. The net was trained using approximately 10,000 cases and evaluated using independent cloud scenarios. The model output consists of liquid water content and brightness temperature as a function of frequency and view direction. Predicted liquid water contents agreed very well with the observed liquid water contents.

\subsubsection{Hardware Development}

Two flight-ready polarimeters developed by WaveBand and Sierra Nevada, Inc. are now available for flight testing of the icing condition detection concepts modeled in RADTRAN and with the neural network. The polarimeters provide the four Stokes parameters enabling the potential detection of drizzle size and larger drops, and ice crystals. Initial flight tests have been conducted but explicit corroborative cloud microphysical information was not available for those first flights. These or similar frequency sensors are also currently planned for flight on the fully instrumented NASA-GRC icing research aircraft within the next several years.

\subsection{Remote Sensing Validation Method Development}

\subsection{Background}

Verification and validation of the accuracy of the remote sensing instrumentation requires concurrent in-situ measurement of the atmospheric conditions of interest. A large suite of suitable instruments have been developed for use on aircraft and provide valuable V\&V data. However, access to instrumented research aircraft is limited and another method for in-situ characterization of the atmosphere has been identified. Standard, commercially available balloon-borne radiosondes are used to provide a limited number of atmospheric parameters, specifically temperature and relative humidity as a function of altitude 
and position. These sondes lack the ability to measure liquid water content, which is vital to determining the level of severity of the icing hazard. NASA has undertaken an effort to develop a LWC sensor which is suitable for use on disposable radiosonde.

\subsection{Instrumentation}

The radiosonde system used by NASA is a Sippican Model W-9000 Meteorological System, an integrated hardware and software package that provides meteorological profiles through the use of telemetered radiosonde data and GPS location data. Temperature and humidity are directly measured, while pressure is calculated from GPS data and the Standard Atmosphere. Temperature, with an accuracy of $0.2^{\circ} \mathrm{C}$ is obtained using a standard rod thermistor, positioned at the end of an arm to remove it from the close proximity of the sonde case. A deposited carbon film on an acrylic substrate is used for humidity measurement with a response time of typically less than one second. Comparison of GPS positional data from the sonde and the ground station is used to calculate sonde altitude, latitude and longitude, its velocity with respect to the launch site and rate of ascent. We have recently upgraded this system to the Lockheed Martin Sippican Model LMG6 which uses the same sensor technology but with improved data acquisition signal processing. Data from radiosondes were used during the MWISP, AIRS I, and AIRS II field studies to develop the remote sensing instruments. Figure 8 shows a comparison of data between the Radiometrics 3000 radiometer (blue trace) and the radiosonde (red trace) taken during AIRS II (Ref. 23). Temperature agreement is very good; that of relative humidity is good, with the exception of those regions where the $\mathrm{RH}$ is rapidly changing. However, the radiosonde cannot measure nor provide an estimate of LWC, the right-most plot in Figure 8.

\subsection{Future Work}

Several approaches have been used to develop a liquid water content probe of sufficiently low mass, power consumption and cost for use on a disposable radiosonde. The ATEK device, which uses a vibrating wire to measure LWC and requires temperatures below freezing, has been flown with some success. However it is no longer available as it never reached commercial status. Innovative Dynamics, Inc., through a SBIR Phase II contract, is currently developing a probe based on optical sensing. Two near-IR laser sources operating at wavelengths of 1310 and $1550 \mathrm{~nm}$ are used to illuminate the cloud.

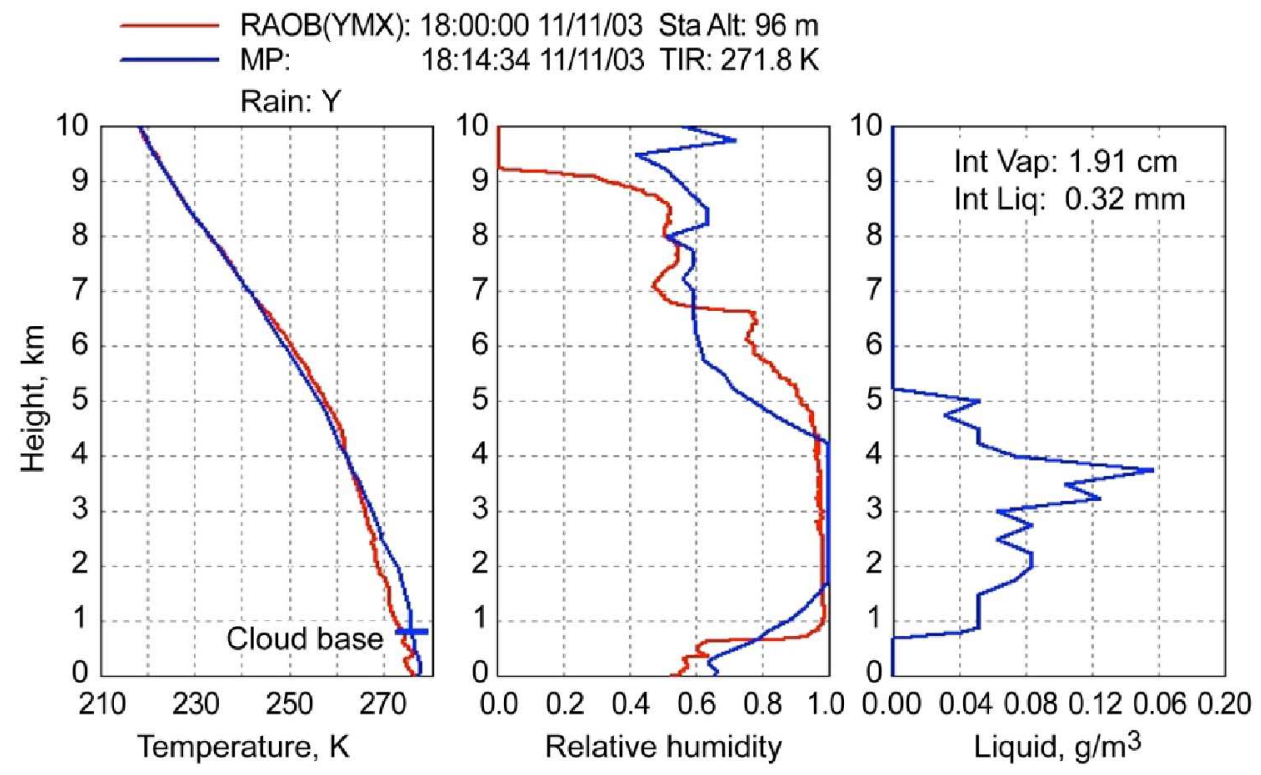

Figure 8.-Comparison of remotely sensed and in-situ data from AIRS II field study. 
The intensity and polarity of the backscattered light is used to determine LWC, droplet size and density and to discriminate between liquid and ice. The concept has been demonstrated in breadboard form and has been extensively tested in a cloud chamber. The prototype flight article is nearing completion, initial testing will be in a tethered balloon configuration. The use of a small, low speed, vertical icing tunnel under development at Glenn is planned to calibrate the probe. Deliverables include three flight-ready probes that will be flown using the Glenn radiosonde system.

\section{References}

1. "2006 NTSB Most Wanted Transportation Safety Improvements," National Transportation Safety Board, NTSB Number SPC-05/06, November 2005.

2. "AOPA Online: AOPA Air Safety Foundation-Accident Database/Analysis," 2008, Aircraft Owners and Pilots Association, Frederick, Maryland, viewed June 10, $2008<\mathrm{http}: / /$ www.aopa.org/asf/ accident_data/>.

3. "Aircraft Accident Report," National Transportation Safety Board, NTSB/AAR-98/04, November 1998.

4. Bernstein, B.C., F. McDonough, M.K. Politovich, B.G. Brown, T.P. Ratvasky, D.R. Miller, C.A. Wolff and G. Cunning, 2005: Current Icing Potential (CIP): Algorithm description and comparison with aircraft observations. J. Appl. Meteor., 44, 969-986.

5. Reehorst, A.L., and Koenig, G.G., "Ground-Based Icing Condition Remote Sensing System Definition," NASA/TM-2001-211102, 2001.

6. F. Solheim, J. Godwin, E. Westwater, Y. Han, S. Keihm, K. Marsh, and R. Ware, "Radiometric Profiling of Temperature, Water Vapor, and Cloud Liquid Water Using Various Inversion Methods," 33, 393-404, Radio Science, 1998.

7. Paluch, I.R., C.A. Knight, and L.J. Miller, "Cloud Liquid Water and Radar Reflectivity of Nonprecipitating Cumulus Clouds," J. Atmos Sci., 53, 1587-1603, 1996.

8. Politovich, M., "Predicting In-Flight Aircraft Icing Intensity," J. Aircraft, 40, 639-644, 2003.

9. K. Knupp, R. Ware, D. Cimini, F. Vandenberghe, J. Vivekanandan, E. Westwater, and T. Coleman, "Ground-Based Passive Microwave Profiling During Dynamic Weather Conditions," submitted to Journal of Atmospheric and Oceanic Technology, 2008.

10. Bernstein, B.C., F.M. McDonough, M.K. Politovich, B.G. Brown, T.P. Ratvasky, D.R. Miller and C.A. Wolff, "Current Icing Potential (CIP): Algorithm Description and Comparison With Aircraft Observations," J. Applied Meteorology, 44, 969-986, 2005.

11. Serke, D., Politovich, M., Reehorst, A., and Gaydos, A., "The Use of X-band Radar to Support the Detection of In-Flight Icing Hazards by the NASA Icing Remote Sensing System During AIRS-II," Proc. SPIE 7088, \#18, 2008.

12. Weng, F., and Grody, N., "Retrieval of Ice Cloud Parameters Using a Microwave Imaging Radiometer," Journal of Atmospheric Sciences, 57, 1069-1081, 2000.

13. Zawadzki, I., Fabry F., and Szyrmer, W., "Observations of Supercooled Water and of Secondary Ice Generation by a Vertically Pointing x-Band Doppler Radar," Atmospheric Research, 59-60, 343-359, 2001.

14. Vivekanandan, J., Zhang, G., and Politovich, M., "An Assessment of Droplet Size and Liquid Water Content Derived From Dual-Wavelength Radar Measurements to the Application of Aircraft Icing Detection," Journal of Atmospheric and Oceanic Technology: vol. 18, no. 11, pp. 1787-1798, 2001.

15. Pazmany, A., "Millimeter-Wave Radar Field Measurements and Inversion of Cloud Parameters for the 1999 Mt. Washington Icing Sensor Project," NASA/CR -2001-211103, August 2001.

16. Pazmany, A., and Mead, J., "Estimation of LWC and Drop Size From Multi-Frequency Radar Reflectivity Profiles With an Artificial Neural Network," 2000 NASA In-Flight Icing Remote Sensing Workshop, November 2000. 
17. Quadrant Engineering, "Evaluation of Technologies for the Design of a Prototype In-Flight Remote Aircraft Icing Potential Detection System," Final R\&D Report, Contract No. DACA39-97-M-1476, 1998.

18. Ryerson, C., Politovich, M., Rancout, K., Koenig, G., Reinking, R., and Miller, D., "Overview of Mount Washington Icing Sensors Project," NASA/TM-2003-212453, AIAA-2000-0488, 2003.

19. Grody, N., "Remote Sensing From Satellites Using Microwave Radiometry," American Meteorological Society Microwave Radiometry Short Course, January 1997.

20. Savage, R., Lines, R., Cole, J., and Koenig G., "A Passive Microwave Icing Avoidance System (MIAS)," Paper P12.9, Proceedings of the American Meteorological Society 8th Conference on Aviation, Range, and Aerospace Meteorology, pp. 457-461, January 1999.

21. Falcone, V., Abreu, L., and Shette, E., "Atmospheric Attenuation of Millimeter and Submillimeter Waves: Models and Computer Code," AFGL-TR-79-0253, Air Force Geophysics Laboratory, 1979.

22. Massie, D., Koenig, G., and Ryerson, C., "Using RADTRAN to Simulate an Aircraft Microwave Radiometer to Detect Icing Potential," 23rd Army Science Conference, Environmental and Geosciences, December 2002.

23. Brinker, D. and Reehorst, A., "Comparison of NASA Icing Remote Sensing System and Balloonsonde Measurements at AIRS II," Paper 9.4, Proceedings of the American Meteorological Society 12th Conference on Aviation, Range, and Aerospace Meteorology, January, 2006. 


\begin{tabular}{|c|c|c|}
\hline \multicolumn{2}{|c|}{ REPORT DOCUMENTATION PAGE } & $\begin{array}{l}\text { Form Approved } \\
\text { OMB No. 0704-0188 }\end{array}$ \\
\hline \multicolumn{3}{|c|}{ 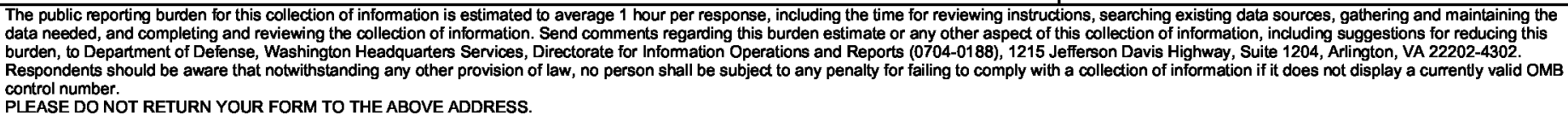 } \\
\hline $\begin{array}{l}\text { 1. REPORT DATE (DD-MM-YYYY) } \\
01-11-2009\end{array}$ & $\begin{array}{l}\text { 2. REPORT TYPE } \\
\text { Technical Memorandum }\end{array}$ & 3. DATES COVERED (From - To) \\
\hline \multirow{3}{*}{\multicolumn{2}{|c|}{$\begin{array}{l}\text { 4. TITLE AND SUBTITLE } \\
\text { Progress Towards the Remote Sensing of Aircraft Icing Hazards }\end{array}$}} & 5a. CONTRACT NUMBER \\
\hline & & 5b. GRANT NUMBER \\
\hline & & 5c. PROGRAM ELEMENT NUMBER \\
\hline \multirow{3}{*}{\multicolumn{2}{|c|}{$\begin{array}{l}\text { 6. AUTHOR(S) } \\
\text { Reehorst, Andrew; Brinker, David; Politovich, Marcia; Serke, David; Ryerson, Charles; } \\
\text { Pazmany, Andrew; Solheim, Fredrick }\end{array}$}} & 5d. PROJECT NUMBER \\
\hline & & 5e. TASK NUMBER \\
\hline & & $\begin{array}{l}\text { 5f. WORK UNIT NUMBER } \\
\text { WBS 609866.02.07.03.04 }\end{array}$ \\
\hline \multicolumn{2}{|c|}{$\begin{array}{l}\text { 7. PERFORMING ORGANIZATION NAME(S) AND ADDRESS(ES) } \\
\text { National Aeronautics and Space Administration } \\
\text { John H. Glenn Research Center at Lewis Field } \\
\text { Cleveland, Ohio 44135-3191 }\end{array}$} & $\begin{array}{l}\text { 8. PERFORMING ORGANIZATION } \\
\text { REPORT NUMBER } \\
\text { E-17090 }\end{array}$ \\
\hline \multirow{2}{*}{\multicolumn{2}{|c|}{$\begin{array}{l}\text { 9. SPONSORING/MONITORING AGENCY NAME(S) AND ADDRESS(ES) } \\
\text { National Aeronautics and Space Administration } \\
\text { Washington, DC 20546-0001 }\end{array}$}} & $\begin{array}{l}\text { 10. SPONSORING/MONITOR'S } \\
\text { ACRONYM(S) } \\
\text { NASA }\end{array}$ \\
\hline & & $\begin{array}{l}\text { 11. SPONSORING/MONITORING } \\
\text { REPORT NUMBER } \\
\text { NASA/TM-2009-215828 }\end{array}$ \\
\hline \multicolumn{3}{|c|}{$\begin{array}{l}\text { 12. DISTRIBUTION/AVAILABILITY STATEMENT } \\
\text { Unclassified-Unlimited } \\
\text { Subject Categories: } 03,35 \text {, and } 47 \\
\text { Available electronically at http://gltrs.grc.nasa.gov } \\
\text { This publication is available from the NASA Center for AeroSpace Information, 443-757-5802 }\end{array}$} \\
\hline
\end{tabular}

\section{SUPPLEMENTARY NOTES}

\section{ABSTRACT}

NASA has teamed with the FAA, DoD, industry, and academia for research into the remote detection and measurement of atmospheric conditions leading to aircraft icing hazards. The ultimate goal of this effort is to provide pilots, controllers, and dispatchers sufficient information to allow aircraft to avoid or minimize their exposure to the hazards of in-flight icing. Since the hazard of in-flight icing is the outcome of aircraft flight through clouds containing supercooled liquid water and strongly influenced by the aircraft's speed and configuration and by the length of exposure, the hazard cannot be directly detected, but must be inferred based upon the measurement of conducive atmospheric conditions. Therefore, icing hazard detection is accomplished through the detection and measurement of liquid water in regions of measured sub-freezing air temperatures. The icing environment is currently remotely measured from the ground with a system fusing radar, lidar, and multifrequency microwave radiometer sensors. Based upon expected ice accretion severity for the measured environment, a resultant aircraft hazard is then calculated. Because of the power, size, weight, and view angle constraints of airborne platforms, the current ground-based solution is not applicable for flight. Two current airborne concepts are based upon the use of either multifrequency radiometers or multifrequency radar. Both ground-based and airborne solutions are required for the future since groundbased systems can provide hazard detection for all aircraft in airport terminal regions while airborne systems will be needed to provide equipped aircraft with flight path coverage between terminal regions.

\section{SUBJECT TERMS}

Aircraft icing; Meteorological radar; Microwave radiometers; Optical radar; Multisensor fusion; Aircraft hazards; Cloud physics; Radiosondes

\begin{tabular}{|c|c|c|c|c|c|}
\hline \multicolumn{3}{|c|}{ 16. SECURITY CLASSIFICATION OF: } & \multirow{2}{*}{$\begin{array}{l}\text { 17. LIMITATION OF } \\
\text { ABSTRACT } \\
\text { UU }\end{array}$} & \multirow{2}{*}{$\begin{array}{l}\text { 18. NUMBER } \\
\text { OF } \\
\text { PAGES } \\
21\end{array}$} & \multirow{2}{*}{$\begin{array}{l}\text { 19a. NAME OF RESPONSIBLE PERSON } \\
\text { STT Help Desk (email:help@sti.nasa.gov) } \\
\text { 19b. TELEPHONE NUMBER (include area code) } \\
\text { 443-757-5802 }\end{array}$} \\
\hline $\begin{array}{l}\text { a. REPORT } \\
\text { U }\end{array}$ & $\begin{array}{l}\text { b. ABSTRACT } \\
\text { U }\end{array}$ & $\begin{array}{l}\text { c. THIS } \\
\text { PAGE } \\
\text { U }\end{array}$ & & & \\
\hline
\end{tabular}



